\title{
UM OLHAR SOBRE OS PRECEDENTES NO SISTEMA JURÍDICO BRASILEIRO
}

\author{
Carlos Henrique Perpétuo Braga ${ }^{1}$ \\ Letícia da Silva Almeida ${ }^{2}$
}

\section{RESUMO:}

Trabalhou-se o tema dos precedentes, permitindo compreender sua importância e superar resistências dos operadores do mundo jurídico. Essa visão tende a ser ultrapassada, porque o cidadão, no Estado Democrático de Direito, não pode se submeter às interpretações individualmente dadas por magistrados, que se apoiam na sua independência para formar o convencimento, ao arrepio de entendimentos consolidados que servem também para pautar o agir da própria população. O CPC/2015 encampou a ideia de observarem os precedentes, vinculando a sua observância, pela segurança jurídica e integridade das decisões. Utilizou-se pesquisa bibliográfica, por meio do método dedutivo e, marco teórico Carnelutti e Chiovenda.

Palavras-Chave: Precedente; Integridade; Segurança jurídica; Estado Democrático de Direito; Judiciário.

\section{A LOOK AT THE PRECEDENTS IN THE BRAZILIAN LEGAL SYSTEM}

\begin{abstract}
:
The theme of the precedents was worked, allowing to understand its importance and overcome resistances of the operators the legal world. This view tends to be surpassed, because citizen, in the Democratic Rule of Law, cannot submit to the individual interpretations given magistrates, who rely on their independence to form persuasion, in spite of consolidated understandings that also to guide the act of the population itself. CPC / 2015 supported the idea of observing the precedents, binding their observance, for legal certainty and integrity of decisions. Bibliographic research was used through the deductive method and theoretical framework Carnelutti and Chiovenda.
\end{abstract}

Keywords: Previous; Integrity; Legal certainty; Democratic state; Judiciary.

\section{INTRODUÇÃO}

Qual é o papel da jurisprudência no sistema judiciário brasileiro? Ela propicia estabilidade? Ela oferece a propalada segurança jurídica aos cidadãos? Ela é, de fato, instrumento de fortalecimento da cidadania e concorre para um Estado Democrático de

\footnotetext{
${ }^{1}$ Mestrando em Direito Público pela Universidade FUMEC. Especialista em Direito Penal, Direito Processual Penal e Direito Processual Civil. Email: pbragacarloshenrique@hotmail.com. Lattes: http://lattes.cnpq.br/6562840642402315

2 Mestra em Direito pela Universidade FUMEC. Professora da Faculdade Pitágoras. Email: leticiaalmeida2613@gmail.com. Lattes: http://lattes.cnpq.br/2572470125751150
} 
Direito? As instâncias inferiores observam a jurisprudência talhada pelas esferas mais altas? E o próprio tribunal que elaborou o acórdão ou editou a súmula, também se fideliza às decisões anteriores?

Este trabalho se entrega a fazer um apanhado preliminar sobre os tópicos que circundam essas inquietações, inquietações essas que estão na ordem do dia, especialmente porque aportaram no Poder Judiciário matérias de grande relevância, o que antes não se verificava, e vêm ganhando acentuada dimensão pela força da mídia e das redes sociais que, implacáveis, acompanham as atividades dos magistrados.

Para além das partes, a sociedade, ávida por justiça, também censura, aplaude, critica e questiona a atuação dos magistrados. No senso comum, "pau que dá em Chico dá em Francisco".

\section{Será?}

Ronald Dworkin (1986), em seu Império do Direito, identificando a importância das decisões judiciais, cravou que importa como os juízes decidem os casos, mesmo porque, segundo Neil MacCormick (2007), em seu "Institutions of Law", o direito é o que o interpretam as cortes.

Por óbvio, a valorização e a legitimidade do precedente matéria passa, também, pela independência e imparcialidade do magistrado.

Dadas as limitações espaciais, utilizando-se o método dedutivo, serão abordados os conceitos mais relevantes, para se pavimentar o caminho que permita compreender a liberdade constitucional conferida aos magistrados, a força do precedente no ordenamento jurídico nacional e a sua importância para a estabilização social.

\section{O JUIZ NO ESTADO DEMOCRÁTICO DE DIREITO}

À partida, é preciso destacar que o Judiciário se entrega a funções diferentes, a depender da qualidade do Estado ao qual se vincula, se democrático ou autoritário.

É inegável, nesse sentido, que cada Estado exija de seus juízes papéis e responsabilidades compatíveis com as necessidades específicas.

No Brasil, com o alargamento dos direitos individuais e coletivos inseridos na Constituição da República Federativa do Brasil de 1988 (CR/88), o Poder Judiciário assumiu 
um protagonismo acentuado, desenvolvendo papéis historicamente reservados e ligados as funções Legislativa e Executiva do Estado.

O Estado Democrático de Direito, com a nova Constituição (CR/88), proporcionou uma abertura à jurisdição, o que, se por um lado, ampliou os horizontes da cidadania para fazer valer os seus "direitos", motivo pelo qual se incrementou sobremaneira o número de demandas (JUSTIÇA EM NÚMEROS 2018), por outro, conduziu à situação de serem os juízes tidos como usurpadores de funções que não lhe eram constitucionalmente afetas.

Por consequência, o Poder Judiciário passou por significativas alterações em sua formatação, alçando a condição de concretizador dos direitos constitucionalmente tutelados à medida que abandona a de mero aplicador das leis.

De fato, o cumprimento dos mandamentos constitucionais exigiu uma maior valorização do processo, pois este, no Estado Democrático de Direito, passou a retratar o ideal de justiça.

Voltando ao Magistrado, essa importância que lhe fora conferida pelo novo texto constitucional exige que se analise a sua postura como julgador, pois, valendo-se do processo e manejando "princípios", pode se afastar da lei, criando o direito de forma idiossincrática.

O temor é de que essa discricionariedade, que é salutar, invada o terreno impróprio da parcialidade. Nesta, as convicções e as predileções pessoais assumem primazia relativamente aos elementos dos autos. Já aquela, a discricionariedade, apoia-se em outros valores:

Em rigor, uma decisão judicial jamais será política no sentido de livre escolha, de discricionariedade plena. Mesmo nas situações que, em tese, comportam mais de uma solução plausível, o juiz deverá buscar a que seja mais correta, mais justa, à luz de elementos do caso concreto. O dever de motivação, mediante o emprego de motivação racional e persuasiva, é um traço distintivo relevante da função jurisdicional e da a ela uma específica legitimação (BARROSO, 2012, p. 29).

Assim, nessa ordem de ideias, é indispensável que o juiz tenha sua liberdade de decidir preservada, não podendo, entretanto, fazer opções à margem das balizas constitucionais.

\section{A APLICAÇÃ̃ DO DIREITO: UMA VISÃO A PARTIR DO SÉCULO XX}


Qual o papel que efetivamente toca ao juiz, enquanto protagonista da relação processual?

No curso do século XX, notadamente em razão do positivismo jurídico, a aplicação do direito pelos tribunais limitava-se à discricionariedade judicial, ou seja, o juiz escolhia, entre as opções oferecidas pela lei, aquela que julgasse mais conveniente e apropriada.

Segundo Willian Soares Pugliese:

[...] a interpretação e a fundamentação judicial que explicasse a interpretação era, de certo modo, algo secundário, a ser tratado apenas à luz do critério da validade. Apesar de a decisão judicial ser o ato 'autêntico' que aplicaria o Direito, sua justificação não era o ponto central das obras positivistas (PUGLIESE, 2017, p. 2).

Interessante observar que a codificação se mostrou igualmente importante para relegar a um segundo plano o papel do Juiz, mesmo porque:

[...] a ideia dos Códigos era a de se antecipar a todas as situações jurídicas e estabelecer regras claras para sanar qualquer problema com o respaldo do Poder Legislativo. Não havia por que o juiz fazer parte dessa interlocução: seu papel era apenas o de avaliar os fatos de um caso, depreender as regras válidas e aplicáveis àquela determinada situação e, com isso, apresentar solução às partes (PUGLIESE, 2017, p. 2).

O raciocínio simples e direto que sugeria a mera aplicação da lei ganha contornos mais inquietantes, a partir do momento em que surgem os conceitos vagos e as cláusulas gerais, que reclamam uma atividade mais intensa do intérprete.

Com efeito, as constituições, ao consagrarem direitos fundamentais, não equacionam casos individuais, pelo que "parte da doutrina passa a observar que o Direito não se restringe a um aspecto de aplicação de normas, mas também contém um elemento de intencionalidade pelo qual ele será interpretado" (PUGLIESE, 2017, p. 2).

Essa guinada fez com que passassem a importar os fundamentos da decisão, o que trouxe os magistrados ao centro das atenções: era importante entender e compreender a forma como eles decidem os casos.

Não bastasse, essa maior autonomia conferida ao juiz em seu poder de interpretar propiciava o surgimento de vários resultados possíveis para um determinado caso, reduzindo, por óbvio, a certeza e a segurança.

Assim, ganha força o papel das próprias decisões judiciais, porque deveriam orientar e direcionar a aplicação e a interpretação dos dispositivos legais. 
Esses novos contornos, insista-se, semeariam segurança jurídica, uniformizando o tratamento dispensado a casos similares e, mais que isso, esvaziando o caráter artesanal, porque não singular, dos atos decisórios.

No Brasil, constata-se um movimento, ainda que tímido, em prol do respeito às decisões.

Isso decorre, dentre outros fatores, pelo fato de se ter uma sociedade eminentemente demandista, que abarrota os tribunais de recursos, e, mais que isso, da exposição das instâncias superiores, que, surpreendentemente, não são absolutamente fiéis aos seus próprios julgados ${ }^{3}$.

Essa última constatação agride, de maneira inquestionável, o art. 926 do Código de Processo Civil (BRASIL, 2015), que impõe aos tribunais movimentos que permitam a uniformização de sua jurisprudência, tornando-a integral, estável e coerente.

É necessário, pois, no âmbito dos tribunais, fomentar a consciência quanto à importância do precedente para a segurança jurídica, mesmo porque ele não leva ao engessamento do direito, mas, ao contrário, permite a sua mutação, desde que sejam observadas as garantias implícitas à previsibilidade.

Essa preparação é indispensável, porque, ao que adverte Luís Roberto Barroso:

[...] questões relevantes do ponto de vista político, social ou moral estão sendo decididas, em caráter final, pelo Poder Judiciário. Trata-se, como intuitivo, de uma transferência de poder para as instâncias judiciais, em detrimento das instâncias políticas tradicionais, que são o Legislativo e o Executivo. Essa expansão da jurisdição e do discurso jurídico constitui uma mudança drástica no modo de se pensar e de se praticar o direito no mundo romano-germânico. Fruto da conjugação de circunstâncias diversas, o fenômeno é mundial, alcançando até mesmo países que tradicionalmente seguiram o modelo inglês - a chamada democracia do estilo de Westminster -, com soberania parlamentar e ausência de controle de constitucionalidade (BARROSO 2018, 44-45).

É de se frisar que a judicialização decorre da previsão constitucional ao direito de ação, não sendo uma opção política do Judiciário. Afinal, não é dado ao Poder Judiciário furtar-se ao pronunciamento sobre as diversas questões que lhe são submetidas.

\section{A FORÇA DAS DECISÕES JUDICIAIS E O PODER LEGISLATIVO}

\footnotetext{
${ }^{3}$ É emblemático o caso da presunção de inocência, afastado pelo Plenário do STF, em fevereiro de 2016, HC 126292, e ignorado pelo Ministro Celso de Melo, em junho daquele ano, em decisão monocrática, lançada no HC 135100.
} 
Há que se pontuar que a aprovação do Código de Processo Civil - Lei 13.105, de 16 de março de 2015, valorizou sobremaneira os precedentes, homenageando a Teoria dos Precedentes.

Evidentemente, essa nova guinada exige uma consistência teórica dos operados do Judiciário para a utilização dos novos dispositivos legais, sob pena de se materializar uma invasão da competência do Poder Judiciário na esfera de atuação do Poder Legislativo.

As súmulas e os precedentes, utilizadas sem o cuidado que a interpretação gera, podem implicar manifesta contraposição ao que estabelece a lei, fonte primária do direito, e produto de intensa discussão na sociedade pelo parlamento.

Em outras palavras, o estabelecimento de efeito vinculante às decisões leva à equiparação destas à lei.

O tema mereceu a preocupação de Nelson Nery Júnior e Rosa Maria de Andrade (2015).

Segundo referidos autores, o art. 927 do Código de Processo Civil traduz "um comando que considera esses preceitos abstratos e de caráter geral, vale dizer, com as mesmas características de lei” (NERY JÚNIOR; NERY, 2015, p. 1837).

É preciso conciliar o efeito vinculante conferido pelo Código de Processo Civil a algumas decisões judiciais e a função do legislador, sob pena de se ruir a tripartição dos poderes, tão cara à democracia.

Aliás, Chiovenda, que se preocupava com os limites de atuação do Poder Judiciário,mesmo porque sua obra pauta-se na ideia do Estado liberal, divisando as funções jurisdicionais daquelas afetas aos demais poderes, conceituava a jurisdição como sendo a:

\footnotetext{
a função do Estado que tem por escopo a atuação da vontade concreta da lei por meio da substituição, pela atividade de órfãos públicos, da atividade de particulares ou de outros órgãos públicos, já no afirmar a existência da vontade da lei, já no torna-la, praticamente, efetiva (CHIOVENDA, 1969, p. 3).
}

Igualmente relevante para fins dos objetivos desse trabalho é assinalar o papel conferido por Carnelutti ao Juiz, para quem a sua função era a de compor a lide, pelo que ele, o juiz, cria a norma aplicável ao caso concreto (CARNELUTTI, 1958). 
Ambos, portanto, conferiam à lei um papel de supremacia, pelo que o juiz, de forma mecânica, sem nada criar, constatava os fatos, repetia a norma geral, resolvendo questões que lhe eram submetidas.

Esses conceitos clássicos de jurisdição foram se amoldando no tempo, de sorte que suas alterações se apegavam aos contextos culturais e históricos, sem embargo de se ater ao próprio modelo de Estado.

Em apanhado sintético, enumera Willian Soares Pugliese outras razões dadas pelos doutrinadores brasileiros para a evolução do conceito de jurisdição:

Fredie Didier Jr., por sua vez, aponta as transformações na Teoria do Direito como a responsável pela mudança dos conceitos da Teoria do Processo. Já Rosemiro Pereira Leal justifica a mudança de perspectiva como decurso de uma atualização da Teoria do Estado, que não é mais a figura hobbesiana do Leviatã, mas um Estado marcado pelas características de ser 'Democrático de Direito’ (PUGLIESE, 2017, p. 12).

Nas concepções contemporâneas, o papel do juiz é o de tutelar os direitos protegidos pela Constituição e pela legislação infraconstitucional, de modo que o Estado deve não apenas garantir o direito fundamental à tutela jurisdicional, mas, igualmente, proferir uma decisão de mérito, mesmo porque não se pode exigir da lei a capacidade de prever a totalidade das situações de fato levadas ao Judiciário.

Avança-se, ainda, para uma ideia de que o juiz deve preservar e fazer valer a vontade da Constituição, garantindo a igualdade e a proteção dos direitos fundamentais.

Segundo Luiz Guilherme Marinoni:

se a lei passa a se subordinar aos princípios constitucionais de justiça e aos direitos fundamentais, a tarefa da doutrina deixa de ser a de descrever a lei. Cabe agora ao jurista, seja qual for a área de sua especialidade, em primeiro lugar, compreender a lei à luz dos princípios constitucionais de justiça e dos direitos fundamentais (MARINONI, 2005, p. 26).

As diversas formas de se conceituar a jurisdição remetem ao ponto comum de se respeitar a esfera de atuação do legislador.

Afinal, não é dado ao juiz a criação de normas, mas apenas otimização da tutela dos direitos individuais e coletivos, valendo-se, mesmo diante da imprevisão legal, dos princípios que alimentam a Constituição.

\section{AS DECISÕES JUDICIAIS}


Revela-se a decisão judicial como sendo "a declaração judicial que determina uma consequência jurídica" (JAUENIG, 2002, p. 301).

Nessa ordem de ideias, o Código de Processo Civil, na seção relativa aos pronunciamentos do juiz, aponta assumirem as decisões os contornos de sentença, que põe fim à fase cognitiva do procedimento comum e extingue a execução, de decisões interlocutórias, que apesar de sua carga de comando, não se amoldam à sentença, e os despachos, que encampam tudo aquilo que não seja sentença ou decisão interlocutória.

Cita-se:

Art. 203. Os pronunciamentos do juiz consistirão em sentenças, decisões interlocutórias e despachos.

$\S 1$ o Ressalvadas as disposições expressas dos procedimentos especiais, sentença é o pronunciamento por meio do qual o juiz, com fundamento nos art. 485 e 487, põe fim à fase cognitiva do procedimento comum, bem como extingue a execução.

$\S 20$ Decisão interlocutória é todo pronunciamento judicial de natureza decisória que não se enquadre no $\S 10$.

§ 3o São despachos todos os demais pronunciamentos do juiz praticados no processo, de ofício ou a requerimento da parte.

$\S 4$ o Os atos meramente ordinatórios, como a juntada e a vista obrigatória, independem de despacho, devendo ser praticados de ofício pelo servidor e revistos pelo juiz quando necessário (BRASIL, 2015).

A mais importante é a sentença, pela qual se encerra o processo e se definem as consequências jurídicas.

A sua validação exige a presença de três elementos estruturantes, que se resumem no relatório, na fundamentação e na parte dispositiva, sendo certo, ainda, que a segunda parte não pode tangenciar qualquer dos incisos do art. 489, § 1 $1^{\circ}$, do Código de Processo Civil, consoante abaixo colacionado:

Art. 489.§ 1o Não se considera fundamentada qualquer decisão judicial, seja ela interlocutória, sentença ou acórdão, que:

I - se limitar à indicação, à reprodução ou à paráfrase de ato normativo, sem explicar sua relação com a causa ou a questão decidida;

II - empregar conceitos jurídicos indeterminados, sem explicar o motivo concreto de sua incidência no caso;

III - invocar motivos que se prestariam a justificar qualquer outra decisão;

IV - não enfrentar todos os argumentos deduzidos no processo capazes de, em tese, infirmar a conclusão adotada pelo julgador;

V - se limitar a invocar precedente ou enunciado de súmula, sem identificar seus fundamentos determinantes nem demonstrar que o caso sob julgamento se ajusta àqueles fundamentos;

VI - deixar de seguir enunciado de súmula, jurisprudência ou precedente invocado pela parte, sem demonstrar a existência de distinção no caso em julgamento ou a superação do entendimento (BRASIL, 2015). 
Essa disposição, em verdade, vai ao encontro do art. 93, IX, da Constituição da República, que exige a fundamentação de todas as decisões judiciais.

\begin{abstract}
Art. 93. Lei complementar, de iniciativa do Supremo Tribunal Federal, disporá sobre o Estatuto da Magistratura, observados os seguintes princípios: [...]

IX - todos os julgamentos dos órgãos do Poder Judiciário serão públicos, e fundamentadas todas as decisões, sob pena de nulidade, podendo a lei limitar a presença, em determinados atos, às próprias partes e a seus advogados, ou somente a estes, em casos nos quais a preservação do direito à intimidade do interessado no sigilo não prejudique o interesse público à informação (BRASIL, 1988).
\end{abstract}

Limita o Código de Processo Civil o ato decisório do juiz às balizas apresentadas pelos contendores, pelo que não se tolera qualquer manifestação que não coincida com o que querem as partes, consoante art. 492, abaixo transcrito:

Art. 492. É vedado ao juiz proferir decisão de natureza diversa da pedida, bem como condenar a parte em quantidade superior ou em objeto diverso do que lhe foi demandado (BRASIL, 2015).

Impede ainda o referido Código que o prolator da decisão a altere, após publicação, salvo nas situações previamente listadas no art. 494.

Cita-se:

Art. 494. Publicada a sentença, o juiz só poderá alterá-la:

I - para corrigir-lhe, de ofício ou a requerimento da parte, inexatidões materiais ou erros de cálculo;

II - por meio de embargos de declaração (BRASIL, 2015).

No que tange ao segundo grau, anunciou o Código de Processo Civil ser o acórdão “o julgamento colegiado proferido pelos tribunais”, consoante art. 204 (BRASIL, 2015).

Essa constatação é relevante, porque, efetivamente, apenas os atos decisórios de segunda instância podem gerar precedentes e, por consequência, fomentar a vinculação às diversas instâncias do Judiciário.

\title{
6 OS PRECEDENTES
}


Parece consenso que o Código de Processo Civil prevê um conjunto de precedentes que devem ser observados pelos julgadores ${ }^{4}$.

Com isso, não apenas a lei, mas também essas decisões anteriores devem orientar os magistrados na elaboração de suas decisões, considerando, como anteriormente assinalado, que não será tida como motivada a decisão que não seguir precedente ou jurisprudência invocada pela parte, nos termos do art. 489, $\S 1^{\circ}$, VI, do Código de Processo Civil (BRASIL, 2015).

Essa exigência remete-nos ao preâmbulo, considerando o senso comum de ser intolerável que as decisões não sejam coerentes e íntegras. De fato, não parece razoável que haja distorção entre decisões que envolvam o mesmo tema e as mesmas circunstâncias.

No ponto, é salutar a menção ao art. 79 do Regimento Interno do Tribunal de Justiça (TJMG, 2012) que, na tentativa de minimizar a ocorrência de decisões conflitantes e com vistas a emprestar coerência e integridade aos seus acórdãos e mesmo às decisões monocráticas, avança no fenômeno da prevenção, estabelecendo a vinculação de desembargador que tenha conhecido da matéria anteriormente.

Quando se afirma que o Código de Processo Civil prestigiou os precedentes, o tema não se limita ao art. 489.

São de leitura obrigatória, reforçando a assertiva, os art. 926 e 927 do Código de Processo Civil: Art. 926. Os tribunais devem uniformizar sua jurisprudência e mantê-la estável,
integra e coerente.
$\S 1^{0}$ Na forma estabelecida e segundo os pressupostos fixados no regimento interno,
os tribunais editarão enunciados de súmula correspondentes a sua jurisprudência
dominante.
$\S 2^{-}$Ao editar enunciados de súmula, os tribunais devem ater-se às circunstâncias
fáticas dos precedentes que motivaram sua criação.

Art. 927. Os juízes e os tribunais observarão:

I - as decisões do Supremo Tribunal Federal em controle concentrado de constitucionalidade;

II - os enunciados de súmula vinculante;

III - os acórdãos em incidente de assunção de competência ou de resolução de demandas repetitivas e em julgamento de recursos extraordinário e especial repetitivos;

\footnotetext{
${ }^{4} \mathrm{O}$ trabalho não busca enfrentar a discussão sobre a adoção da teoria do precedente judicial no Brasil, assinalando, entretanto, a existência de três grupos que divisam a respeito. No primeiro, tem-se que não se pode falar em precedente judicial no Brasil, porque a eficácia das decisões decorre da lei, ao passo que no "common law", ela é histórico-concreta. No segundo, aceita-se a a adoção de precedente, tendo em vista que a própria lei, em sentido amplo, dá eficácia a determinadas decisões e à própria súmula vinculante. No terceiro, entende-se que o precedente é fruto da atividade jurisdicional, de maneira que é natural a produção de decisões que possam se tornar modelos.
} 
IV - os enunciados das súmulas do Supremo Tribunal Federal em matéria constitucional e do Superior Tribunal de Justiça em matéria infraconstitucional; V - a orientação do plenário ou do órgão especial aos quais estiverem vinculados (BRASIL, 2015).

Também parece consenso na doutrina que esses dispositivos se inspiraram em Ronald Dworkin.

Nessa linha, não podem os capítulos de um romance ser completamente divorciados, isolados, desvinculados. Devem compor "um romance em cadeia", de modo que o capítulo seguinte deve guardar relação estreita com o anterior.

Assim o fazendo, assinala Dworkin, o juiz será fiel ao seu dever de integridade:

Podemos comparar o juiz que decide sobre o que é direito em alguma questão judicial, não apenas com os cidadãos da comunidade hipotética que analisa a cortesia que decidem o que essa tradição exige, mas com o crítico literário que destrinça as várias dimensões de valor em uma peça ou um poema complexo. Os juízes, porém, são igualmente autores e críticos. [...] Em tal projeto (Romance em cadeia), um grupo de romancistas escreve um romance em série; cada romancista da cadeia interpreta os capítulos que recebeu para escrever um novo capítulo, que é então acrescentado ao que recebe o romancista seguinte, e assim por diante. Cada um deve escrever seu capítulo de modo a criar da melhor maneira possível o romance em elaboração, e a complexidade dessa tarefa reproduz a complexidade de decidir um caso difícil de direito como integridade (DWORKING, 2003, p. 275).

Ainda segundo Dworkin, é imprescindível uma linha de argumentos densos para justificar o rompimento na similaridade das decisões.

Não sem razão, recomenda que os juízes estudem não apenas os repertórios jurídicos, mas, igualmente, as anotações parlamentares, identificando as razões e as decisões tomadas pelo poder legislativo. Trata-se de exigência do que denominou convencionalismo.

Por outro lado, o pragmatismo exige que os juízes identifiquem as regras adequadas para o futuro.

Por fim, lembra Francis Ted Fernandes, ainda com o apoio em Dworkin, que "o direito como integridade é diferente: deve partir da concepção atual, considerado o passado como adequação linear - mas com vistas a produzir a melhor decisão no futuro. Deve imprimir um caráter de continuidade ao direito" (FERNANDES, 2016, p. 62).

Essa questão assume relevância, especialmente quando se trata de interpretação, pois se veda ao juiz seguir apenas a sua opinião, de forma arbitrária, preterindo aquilo que vinha sendo decidido. Afinal, a decisão precisa guardar sintonia com o direito em vigor. 
Qualquer direcionamento em contrário pode afrontar a coerência que a ordem jurídica deve apresentar.

Mais, a inconsistência das decisões compromete a estabilidade jurídica, pelo que a sua aceitação parte, também, de uma ideia de adesão. Ainda, elas seriam reflexo de experiências pessoais dos magistrados e, nessa condição, não contribuiriam para a pacificação social, lançando os protagonistas da relação processual ao universo da sorte.

No estado Democrático, ao lado do ideal de justiça, deve-se prestigiar também a segurança, e ambas somente poderão ser alcançadas com uma interpretação coerente.

Portanto, ao determinar que os precedentes sejam observados - art. $489, \S 1^{\circ}$, VI, do Código de Processo Civil (BRASIL, 2015), a integridade deve prevalecer nas decisões judicial, especialmente quando o precedente for invocado pela parte e levaria ao acolhimento de sua tese.

Observam Marinoni, Arenhart e Midiero que:

Existindo precedente constitucional ou precedente federal sobre o caso debatido em juízo, a fidelidade ao direito constitui fidelidade ao precedente. Daí que a ausência de efetivo enfrentamento - mediante a demonstração da distinção - pelo juízo de precedente invocado pela parte constitui omissão relevante na redação da fundamentação. Existindo precedente invocado pela parte, esse deve ser analisado pelo juízo. Se disser efetivamente respeito à controvérsia examinada em juízo, deve ser adotado como razão de decidir. Se não, a distinção entre o caso precedente e o caso concreto deve ser declinada na fundamentação. A ausência de efetivo enfrentamento do precedente constitui violação do dever de fundamentação (art. 489, § $1^{\circ}$ VI, CPC) (MARINONI; ARENHART; MIDIERO, 2015, p. 114).

A inobservância do precedente afigura-se intolerável à medida que implicaria a violação do princípio da "supremacia do legislativo", tão cara a Dworkin, traduzindo uma violação do pacto democrático: as regras existem e devem ser cumpridas no Estado Democrático de Direito:

Porém, não é qualquer princípio que pode ser invocado para justificar a mudança; caso contrário, nenhuma regra estaria a salvo. É preciso que existam alguns princípios com a importância e outros sem importância e é preciso que existam alguns princípios mais importantes que outros. Esse critério não pode depender das preferências pessoais do juiz, selecionadas em meio a um mar de padrões extrajurídicos respeitáveis, cada um deles podendo ser, em princípio, elegível. Se fosse assim, não poderíamos afirmar a obrigatoriedade de regra alguma. Já que, nesse caso, sempre poderíamos imaginar um juiz cujas preferências, selecionadas entre os padrões extrajurídicos, fossem tais que justificassem uma mudança ou uma reinterpretação radical até mesmo da regra mais arraigada. $\mathrm{Na}$ segunda maneira de considerar o problema, um juiz que se propõe a modificar uma 
doutrina existente deve levar em consideração alguns padrões importantes que se opõem ao abandono da doutrina estabelecida; esses padrões são, na sua maior parte, princípios. Esses padrões incluem a doutrina da "supremacia do Poder Legislativo", um conjunto de princípios que exige que os tribunais mostrem uma deferência limitada pelos atos do Poder Legislativo. Eles incluem também a doutrina do precedente, outro conjunto de princípios que reflete a equidade e a eficiência que derivam da consistência. As doutrinas da supremacia do Poder Legislativo e do precedente inclinam em favor do status quo, cada uma delas na sua própria esfera, mas não o impõe. Os juízes, no entanto, não têm liberdade para escolher entre os princípios e as políticas que constituem essas doutrinas também neste caso, se eles fossem livres, nenhuma regra poderia ser considerada obrigatória (DWORKIN, 2010, p. 60-61).

Assim, é salutar que as decisões também se orientem nos precedentes, permitindo que a estabilização do enfrentamento das questões levadas ao Judiciário.

Nesse sentido, por força de lei, tem o magistrado o dever de seguir o precedente, especialmente quando invocado pela parte em abono a sua tese, somente se admitindo que não o faça se identificar razões relevantes.

\section{CONCEITOS CORRELATOS AOS PRECEDENTES}

A menção aos precedentes reclama a demarcação do que efetivamente pode vincular os juízes relativamente ao precedente.

Explica Elpídio Donizetti Nunes que:

É importante esclarecer que o que forma o precedente é apenas a razão de decidir do julgado, a sua ratio decidendi. Em outras palavras, os fundamentos que sustentam os pilares de uma decisão é que podem ser invocados em julgamentos posteriores. As circunstâncias de fato que deram embasamento à controvérsia e que fazem parte do julgado não têm o condão de tornar obrigatória ou persuasiva a norma criada para o caso concreto. Além disso, os argumentos acessórios elaborados para o deslinde da causa (obter dictum) não podem ser utilizados com força vinculativa por não terem sido determinantes para a decisão (NUNES, 2015, p. 85).

À partida, deve ser lembrado que alguns precedentes ostentam força normativa, pelo que obrigam e vinculam os magistrados, em razão da condição de quem as criou. São os "stare decisis", que correspondem à norma criada por uma decisão judicial.

No Brasil, o Superior Tribunal de Justiça e o Supremo Tribunal Federal podem criar a norma - teoria constitutiva -, ao passo que os juízes devem aplicar o precedente criado teoria declaratória. 
Adverte ainda Elpídio Donizetti que os precedentes não podem ser aplicados de qualquer maneira pelos magistrados (DONIZETTI, 2015).

Recorrendo ao magistério de Cruz e Tucci, assinala a necessidade de se empreender o "distinguishing”, porque os precedentes não podem ser invocados indiscriminadamente, forjando semelhanças fáticas inexistentes.

Assim:

Os precedentes vinculantes não devem ser aplicados de qualquer maneira pelos
magistrados. Há necessidade de que seja realizada uma comparação entre o caso
concreto e a ratiodecidendi da decisão paradigmática. É, preciso, em poucas
palavras, considerar as particularidades de cada situação submetida à apreciação
judicial e, assim, verificar se o caso paradigma possui alguma semelhança com
aquele que será analisado. Essa comparação leva o nome de distinguishing, que,
segundo Cruz e Tucci (2004, p. 174), é o método de confronto "pelo qual o juiz
verifica se o caso em julgamento pode ou não ser considerado análogo ao
paradigma". Se não houver coincidência entre os fatos discutidos na demanda e a
tese jurídica que subsidiou o precedente, ou, ainda, se houver alguma
peculiaridade no caso que afaste a aplicação da ratiodecidendi daquele precedente,
o magistrado poderá se ater a hipótese sub judice sem se vincular ao julgamento
anterior (CRUZ; TRUCCI, 2004, P. 174, apud NUNES, 2015).

De qualquer forma, arremata, o mais importante nessa distinção é que haja motivação (art. 93, IX, da CF), pois na fundamentação das decisões judiciais, "o juiz deve identificar exatamente as questões que reputou essenciais ao deslinde da causa", garantindo ao ato decisório a indispensável legitimidade, mesmo porque "a fundamentação será a norma geral, um modelo de conduta para a sociedade, principalmente para os indivíduos que nunca participaram daquele processo, e para os demais órgãos do Judiciário" (BRASIL, 2015)

O “distinguishing” não se confunde com o "overruling”, que consiste na revogação do entendimento paradigmático consubstanciado no precedente.

Ao que pontua Elpídio Donizetti Nunes, “essa técnica imprescinde da modificação dos valores sociais, dos conceitos jurídicos, da tecnologia ou mesmo em virtude de erro gerador de instabilidade em sua aplicação" (NUNES, 2015).

Questão de relevo diz respeito à aplicabilidade desse fenômeno no tempo, porque, havendo a revogação de um precedente, com a respectiva construção de uma nova tese jurídica, ela "passará a reger as relações ocorridas antes da decisão revogadora, mas que ainda estejam sujeitas ao crivo judicial", ensejando o fenômeno da retroatividade plena.

\section{CONCLUSÃo}


Esse levantamento preliminar, que tangenciou alguns temas relevantes acerca do precedente, visa despertar a atenção dos operadores do direito para a sua importância.

O estudo do direito não pode se limitar exclusivamente à norma, sem a análise pedagógica dos casos.

É preciso valorizar os precedentes e, mais que isso, é essencial, no Estado Democrático de Direito, que ele seja produzido com os critérios que respeitem a esfera de atuação do Poder Legislativo.

Em outras palavras, a segurança jurídica, tão cara à sociedade e que deve ser obtida com uma linha coerente de decidir dos tribunais e dos juízes, não deve sacrificar a esfera de atuação do Poder Legislativo. Neste, representado por seguimentos sociais de diversas matizes, deverão ser travados os debates sobre as regras a serem aplicadas.

O Código de Processo Civil foi nessa direção à medida que estabeleceu dispositivos que buscam padronizar as decisões, tornando-as mais previsíveis, coerentes e fiéis ao próprio ordenamento jurídico.

O passo, conquanto embrionário, traduz uma mudança significativa na forma de se fazer o direito, com mais previsibilidade, mais aceitabilidade e, acima de tudo, mais legitimidade social.

No ponto relativo à legitimidade social, frisa-se que não se quer um Poder Judiciário afinado com as ruas, mesmo porque isso não coincide com a sua missão constitucional. Não raras as vezes, há que decidir contramajoritariamente.

Todavia, é preciso, como enfatizado no preâmbulo, que as decisões judiciais, enquanto pautadas em premissas similares, apontem também no mesmo sentido.

Em assim ocorrendo, com a valorização do precedente, poder-se-á contribuir para sedimentar o Estado Democrático de Direito.

\section{REFERÊNCIAS}

BRASIL. Código de Processo Civil. Sancionado em 16 de março de 2015. Disponível em: http://www.planalto.gov.br/ccivil_03/_Ato2015-2018/2015/Lei/L13105.htm. Acesso em: 20 jan. 2019. 
BRASIL. Constituição Federal de 1988. Promulgada em 5 de outubro de 1988. Disponível em: http://www.planalto.gov.br/ccivil_03/Constituicao/Constituicao.htm. Acesso em: 20 jan. 2019.

BARROSO, Luís Roberto. A judicialização da vida e o papel do Supremo Tribunal Federal. $1^{\text {a }}$ reimp. Belo Horizonte: Fórum. 2018.

BORGES, Ronaldo Souza. A prova pela presunção na formação do convencimento judicial. D'PLÁCIDO Editora: Belo Horizonte. 2016

CARNELUTTI, Francesco. Diritto e processo. Napoli: Morano, 1958.

CHIOVENDA, Giuseppe. Instituições de direito processual civil. São Paulo: Saraiva, 1969, v. 2.

DWORKIN, Ronald. Law's Empire. Cambridge: Harvard University Press, 1986.

DWORKIN, Ronald. Levando os direitos a sério. Trad. Nelson Boeira. São Paulo: Martins Fontes, 2010.

FERNANDES, Francis Ted. O Sistema de Precedentes no CPC, o dever de integridade e coerência e o livre convencimento do juiz. Disponível em: https://www.migalhas.com.br/dePeso/16,MI248774,81042-

$\mathrm{O}+$ sistema+de+precedentes+do+novo+CPC+o+dever+de+integridade+e. Acesso em: 17 jan. 2019.

JAUENIG, Othmar. Direito Processual Civil. Coimbra: Almedina, 2002.

MacCORMICK, Neil. Institutions of Law: an essay in legal theory. Oxford: Oxford University Press, 2007.

MARINONI, Luiz Guilherme. A jurisdição no Estado Contemporâneo. In: MARINONI, Luiz Guilherme (Coord.). Estudos de Direito Processual Civil. São Paulo: Revista dos Tribunais, 2005.

MARINONI, Luiz Guilherme; ARENHART, Sérgio Cruz; MITIDIERO, Daniel. Novo CPC comentado. São Paulo: Editora Revista dos Tribunais, 2015.

NERY JR., Nelson; NERY, Rosa Maria de Andrade. Comentários aos Código de Processo Civil. São Paulo: Revista dos Tribunais, 2015.

NUNES, Elpídio Donizetti. A força dos precedentes no novo Código de Processo Civil. Disponível em: https://elpidiodonizetti.jusbrasil.com.br/artigos/155178268/a-forca-dosprecedentes-do-novo-codigo-de-processo-civil. Acesso em: 17 jan. 2019.

PUGLIESE, Willian Soares. Princípios da jurisprudência. Belo Horizonte: Arraes Editora, 2017. 
STRECK, Lenio Luiz. Verdade e Consenso: constituição, hermenêutica e teorias discursivas. São Paulo: Saraiva, 2011. 4. ed.

TRIBUNAL DE JUSTIÇA DO ESTADO DE MINAS GERAIS. Resolução do Tribunal Pleno $\mathbf{n}^{\mathbf{0}}$ 03/2012. Regimento Interno do Tribunal de Justiça do Estado de Minas Gerais. Disponível em: https://www8.tjmg.jus.br/institucional/at/pdf/rp00032012.pdf. Acesso em: 19 jan. 2019.

TUCCI, José Rogério Cruz e. Precedente Judicial como Fonte do Direito. São Paulo: Revista dos Tribunais, 2004. 